\title{
DIÁLOGOS TEÓRICO-METODOLÓGICOS: ANÁLI- SE DE DISCURSO CRÍTICA E REALISMO CRÍTICO
}

\author{
Viviane C. V. S. Ramalho
}

\section{RESUMEN}

El objetivo de este trabajo es discutir aspectos del Realismo Crítico, desarrollado por Roy Bhaskar (1978, 1989, 1993), que es una de las bases epistemologicas del Análisis Crítico del Discurso (ACD) (Chouliaraki \& Fairclough, 1999; Fairclough, 2003). Esa base inspira aspectos de la concepción de discurso, de acción social, y del abordaje teórico-metodológico del ACD para estudios del lenguaje como práctica social. La intención es acercar las dos propuestas para estudios críticos de la sociedad.

PALABRAS-CLAVE: Ciencias Sociales Críticas; Realismo Crítico; Análisis Crítico del Discurso.

\section{APRESENTAÇÃo}

O objetivo deste trabalho é discutir aspectos de uma das bases científicas que sustentam a Análise de Discurso Crítica (ADC), desenvolvida por Fairclough (1989, 2001[1992], 1995, 2003) e Chouliaraki \& Fairclough (1999)1: o Realismo Crítico (RC), um movimento filosófico de origem britânica, cujo expoente é reconhecido no filósofo contemporâneo Roy Bhaskar (1978, 1989, 1993). Muitos aspectos da proposta da ADC de oferecer suporte científico para estudos transdisciplinares da linguagem (ou semiose, para incluir outras formas de manifestação lingüística) como prática social apóiam-se em princípios do RC.

A idéia central do Realismo é a de que há um mundo real, incluindo o mundo social, que existe independentemente de nós e de nosso conhecimento, percepção ou concepção sobre ele. O Realismo Crítico, discutido aqui, é uma

\footnotetext{
${ }^{1}$ Outras influências são abordadas em Ramalho (2005) e Resende \& Ramalho (2004, 2006).
} 
versão de Realismo. Para essa versão crítica, o mundo real, que existe independentemente de nosso conhecimento sobre ele, é um sistema aberto, mutável, e constituído por diferentes estratos (físico, biológico, semiótico, químico etc.) e domínios (real, actual e empírico). Essa visão de realidade mutável, que pressupõe uma concepção transformacional da atividade social, traz, no mínimo, quatro implicações teórico-metodológicas importantes para a ADC.

Primeiro, a ADC considera que a semiose, por um lado, na qualidade de um desses estratos com seus mecanismos gerativos e poderes causais particulares, internaliza traços de outros estratos, assim como tem efeitos sobre eles. Por outro lado, na qualidade de um dos cinco momentos constituintes de práticas sociais, internaliza traços de outros momentos, bem como é internalizado por eles, de maneiras imprevisíveis, sem se reduzirem a um.

Segundo, reconhecida tal relação dialética ${ }^{2}$ entre domínios, estratos com seus mecanismos e momentos constituintes de práticas sociais, a abordagem teóricometodológica da ADC preocupa-se em contemplar, por meio da crítica explanatória, níveis mais profundos da realidade, e não apenas aspectos semióticos.

Terceiro, inspirada no RC, a ADC enfoca a semiose como "prática social", ou seja, seu interesse não se volta exclusivamente para "ações individuais" ou para "estrutura social", mas, sim, para o fluxo de práticas sociais, que representam o ponto de conexão entre estrutura e agência, implicando interdependência causal entre as duas entidades. A estrutura social, incluindo o sistema semiótico, é concebida simultaneamente como aquilo que possibilita e constrange a ação humana, assim como aquilo que resulta dela.

Finalmente, a ADC descarta a possibilidade de pesquisas científicas acessarem diretamente, por exemplo sem passar pelo crivo do pesquisador, o estrato empírico da realidade. Nessa mesma perspectiva, pode ser apontada a influência do RC na posição "crítica" da ADC, ou seja, em sua inclinação emancipatória. Essas implicações teórico-metodológicas do RC podem ser apontadas como algumas características que contribuem para distinguir a ADC de outras vertentes de análise de discurso.

\footnotetext{
${ }^{2}$ O termo mais adequado aqui seria "transformacional” e não "dialética”, uma vez que Bhaskar (1989) propõe um modelo "transformacional" de atividades sociais. Entretanto, preferimos manter o termo "dialética" pelo fato de ser o mais usual em ADC e também por ser utilizado pelo autor em obras posteriores (Bhaskar, 1993, citado em Curry, 2000: 104).
} 
A fim de discutir, de maneira sucinta, o diálogo que essas duas ciências mantêm, divido este texto em duas partes principais. Na primeira parte, apresento aspectos tanto da perspectiva filosófica do RC, o Realismo Transcendental, quanto de sua perspectiva teórico-metodológica, o Naturalismo Crítico. $\mathrm{Na}$ segunda parte, além de apresentar, de maneira sucinta, a ADC, aproximo essa abordagem da linguagem do $\mathrm{RC}$, levantando pontos de diálogo entre as duas disciplinas.

\section{Realismo CRítico}

O termo "Realismo Crítico" deriva de um hibridismo entre "realismo transcendental" e "naturalismo crítico", como Bhaskar (1989: 190)³ explica:

Chamei minha filosofia geral da ciência de "realismo transcendental" e minha filosofia específica das ciências humanas de "naturalismo crítico". Aos poucos, as pessoas começaram a misturar os dois e a referir-se ao híbrido como "realismo crítico". Ocorreu-me que havia boas razões para não me objetar ao hibridismo. Para começar, Kant havia chamado seu idealismo transcendental de "fillosofia crítica". O realismo transcendental tinha o mesmo direito ao título de realismo crítico.

Como o autor esclarece, o RC apresenta dois aspectos principais: um mais geral, o "realismo transcendental", relacionado à filosofia geral da ciência, e outro mais específico, o "naturalismo crítico", voltado para teoria e metodologia em ciências sociais. Na seção 1.1, ocupo-me do aspecto mais geral e, na seção 1.2 , procuro discutir o segundo aspecto.

\subsection{Aspectos filosóficos do Realismo Crítico: Realismo Transcendental}

A comparação feita por Bhaskar entre o RC e o Idealismo Transcendental de Kant não é gratuita. Bhaskar faz uma inversão realista da filosofia de Kant, incluindo a inversão do argumento transcendental do idealismo: "Como o conhecimento empírico é possível?".

\footnotetext{
${ }^{3}$ Citado em Collier (1994: xii).
} 
O idealismo transcendental teria como ponto de partida não as coisas exteriores, mas o eu, o sujeito ou a consciência, uma vez que Kant (1724-1809) "não só negou que a mente aceitasse passivamente os elementos que lhe chegavam pela via dos sentidos, como afirmou que a mente determina o objeto, em virtude de certos princípios necessários, universais e apriorísticos" (Rios, 1987: 566-567). O termo “idealismo", portanto, relaciona-se à importância conferida às idéias, ao passo que o termo "transcendental" remete à preocupação de tornar explícito um conhecimento apenas implícito, que pode ser relativo à ciência ou mesmo a outras atividades (Collier, 1994).

Ao propor seu Realismo Transcendental, Bhaskar inverte a abordagem "idealista e individualista" do idealismo transcendental. Idealista porque se ocupa mais com idéias sobre o mundo do que com o mundo em si, e individualista porque se ocupa com idéias universais, válidas em princípio para toda mente humana, desconsiderando práticas sociais particulares, em diferentes tempos e espaços. A partir da concepção de que os princípios necessários que usamos para compreender e identificar objetos do mundo não são exteriormente determinados, universais ou apriorísticos, mas, sim, social e historicamente construídos, Bhaskar propõe o seguinte argumento transcendental realista: "Como experimentos são possíveis?" (Collier, 1994: 34). Se, para o idealismo, o mais importante nas ações humanas são as idéias, para o realismo, ao contrário, o que importa são "as realidades e os fatos que devem reger as ações humanas" (Rios, 1987: 566).

Enquanto Kant se preocupa com as "precondições da possibilidade do conhecimento", Bhaskar ocupa-se com as "precondições da possibilidade da atividade social". O tipo de pergunta, portanto, que orienta pesquisas sociais, segundo o RC, não é de cunho essencialmente epistemológico, mas ontológico. A partir desse argumento transcendental realista, próprio do aspecto da filosofia geral do RC, são formulados os princípios e as concepções do Naturalismo Crítico, o aspecto mais específico do RC, relacionado à aplicação dessa filosofia às ciências humanas. 
1.2 Aspectos teórico-metodológicos do Realismo Crítico: o Naturalismo Crítico

No Naturalismo Crítico, que se refere a "possíveis implicações do realismo transcendental nas ciências humanas" (Collier, 1994: xi), o argumento transcendental "Como experimentos são possíveis?" dá origem a outro argumento: "Que propriedades pessoas e sociedades possuem que podem torná-las possíveis objetos de conhecimento?" (Bhaskar, 1978: 13), ou "Como deve ser o mundo para que a ciência seja possível?" (Tozzi, 2000: 79).

Ao contrário das tradições naturalistas e antinaturalistas - essencialmente positivistas e empiristas -, essa vertente de Naturalismo sustenta que não pode haver unidade de método entre as ciências naturais e sociais. Além do idealismo, o RC questiona a visão naturalista de um mundo, natural e social, regular, estável, previsível, que pode ser investigado por meio da observação de eventos que se sucedem com regularidades empiricamente observáveis. O RC sustenta que as ciências naturais e sociais não podem compartilhar do mesmo método, uma vez que o mundo natural e o mundo social são diferentes, na medida em que a existência do segundo, mas não do primeiro, depende da ação humana.

Como defende Bhaskar (1989: 38), diferentemente das estruturas naturais, as estruturas sociais, que apresentam permanência apenas relativa, não existem independentemente das atividades que elas governam e das concepções dos agentes sobre o que estão fazendo em suas atividades. As propriedades que tornam sociedades possíveis objetos de conhecimento pressupõem ação humana e mutabilidade. Por esse motivo, para que a ciência social seja possível, o mundo deve ser concebido como "estratificado - isto é, estruturado, diferenciado - e mutável” (Bhaskar \& Callinicos, 2003: 98). Os realistas críticos assumem uma "ontologia estratificada", segundo a qual o mundo é um sistema aberto, constituído por diferentes domínios (real, actual e empírico) ${ }^{4}$ e diferentes estratos que operam simultaneamente (físico, químico, biológico, econômico, semiótico etc.), cada qual com suas estruturas distintivas e mecanismos gerativos, causando efeitos imprevisíveis no mundo.

\footnotetext{
${ }^{4}$ Os termos originais em Bhaskar (1978: 56) são real, actual e empirical.
} 


\subsection{Mapa ontológico do Realismo Crítico}

Para o RC, o mundo não é constituído apenas pelo domínio empírico, como quer o realismo empírico, mas por três domínios ontológicos: o real, o actual e o empírico. Bhaskar (1978: 13) sumariza essa estratificação no seguinte mapa ontológico:

Quadro 1 - Mapa ontológico do Realismo Crítico

\begin{tabular}{lccc}
\hline Mecanismos & $\begin{array}{c}\text { Domínio do } \\
\text { real }\end{array}$ & $\begin{array}{c}\text { Domínio do } \\
\text { actual }\end{array}$ & $\begin{array}{c}\text { Domínio do } \\
\text { empírico }\end{array}$ \\
Eventos & $\checkmark$ & & \\
Experiências & $\checkmark$ & $\checkmark$ & \\
\hline
\end{tabular}

Fonte: Bhaskar (1978: 13), recuperado em Collier (1994: 44).

O "real" é, como define Sayer (2000: 09), "o que quer que exista, seja natural ou social, independentemente de ser um objeto empírico para nós e de termos uma compreensão adequada de sua natureza". É o domínio dos objetos, suas estruturas, mecanismos e poderes causais. Sejam físicos, como minerais, ou sociais, como burocracias, esses objetos "têm uma certa estrutura e poderes causais, isto é, capacidade de se comportarem de formas particulares, e tendências causais ou poderes passivos, isto é, susceptibilidades a certas formas de mudança." Neste domínio, mecanismos gerativos de diversos estratos (físico, biológico, social, semiótico, e outros) operam simultaneamente com seus poderes causais, gerando efeitos imprevisíveis nos outros domínios, relativos a eventos e experiências. Como Sayer (2000: 11) exemplifica,

fenômenos sociais são emergentes de fenômenos biológicos, que são, por seu turno, emergentes dos estratos físicos e químicos. Assim, a prática social da conversação depende do estado fisiológico dos agentes, incluindo os sinais enviados e recebidos em torno de nossas células nervosas, mas a conversação não é redutível a estes processos fisiológicos. [...] Embora nós não precisemos voltar ao 
nível da biologia ou da química para explicar os fenômenos sociais, isto não significa que os primeiros não tenham efeito sobre a sociedade. Tampouco significa que podemos ignorar a maneira pela qual afetamos estes estratos, por exemplo, através da contracepção, medicina, agricultura e poluição.

A operação de qualquer mecanismo "gerativo" (aquele que possui certo poder) desses diferentes estratos é sempre mediada pela operação simultânea de outros, de forma tal que não são redutíveis a um e sempre dependem (e internalizam traços) de outros ${ }^{5}$. Por isso, não há necessidade de voltar ao estrato da biologia, da física ou da química para investigar fenômenos sociais, a exemplo da interação pela fala, mas isso não implica a anulação de efeitos biológicos, físicos, químicos sobre a sociedade. Da mesma forma, fenômenos sociais têm efeitos sobre outros estratos ou, em outros termos, contribuem para a "emergência" - "situações em que a conjunção de duas ou mais características ou aspectos dão origem a novos fenômenos" (Sayer, 2000: 11) - de fenômenos de outras naturezas.

Se o "real" é o domínio das estruturas, mecanismos e poderes causais dos objetos, o "actual", como Sayer (2000: 10, destaques meus) ainda explica, refere-se a "o que acontece se e quando estes poderes são ativados", ou seja, àquilo que esses poderes fazem e ao que ocorre quando eles são ativados. Com base na distinção marxista entre "força de trabalho" e "trabalho", o referido autor apresenta um bom exemplo para distinguir os dois domínios. A primeira (a capacidade de desempenhar trabalho), juntamente com as estruturas físicas e mentais das quais ela deriva, corresponde ao nível do real. O segundo, o trabalho, como exercício dessa capacidade ou desse poder, e seus efeitos, pertence ao domínio do actual. Este é, portanto, o domínio dos eventos, que passam por nossa experiência ou não, e que se localiza entre o mais abstrato (estruturas e poderes) e o mais concreto (eventos experienciados).

O “empírico", por fim, é o domínio das experiências efetivas, a parte do real e do actual que é experienciada por atores sociais. Se o real é o domínio dos poderes causais e o actual é o domínio dos eventos em que se acionam esses

\footnotetext{
${ }^{5}$ Sayer (2000: 26) pondera que, a despeito da metáfora mecânica, efeitos causais de mecanismos não são previsíveis na vida social, que é um sistema aberto.
} 
poderes, o empírico, por sua vez, é o que se percebe da ativação desses poderes no domínio dos eventos experienciados. Em outros termos, é o que se sabe do real e do actual, o que não esgota a possibilidade do que tenha acontecido, ou poderia ter acontecido. Como implicação crucial dessa ontologia estratificada, Sayer (2000: 11, acréscimos meus) aponta "o reconhecimento da possibilidade de que os poderes podem existir mesmo quando não exercidos [real], e, assim, que aquilo que aconteceu [actual] ou aquilo que se sabe ter acontecido [empírico] não exaure o que poderia ter acontecido ou tudo que aconteceu".

$\mathrm{O}$ RC considera que não é possível se ter acesso direto ao domínio do real - das estruturas em que mecanismos operam. Esse domínio não pode ser alcançado senão a partir de nosso conhecimento sobre ele, ou seja, a partir do actual e do empírico. Os realistas críticos consideram, nessa perspectiva, uma "falácia epistêmica" pretender, por um lado, estudar o "mundo real" de maneira "objetiva", visto que só podemos estudar o mundo real passando pelo filtro de nossas experiências, e, por outro, conceber o mundo como constituído apenas pelo domínio empírico, ou seja, por aquilo que experienciamos.

Tal concepção tradicional de "mundo empírico" reduz, segundo Bhaskar (1978: 36), os três domínios ontológicos a um. Reduz "o que é” a "o que sabemos sobre", e nem sempre "o que sabemos sobre" elimina todas as possibilidades do que "realmente é". O que sabemos sobre o mundo é mediado por crenças, valores, atitudes, histórias, ideologias, concepções teóricas, experiências, logo só podemos falar sobre "o que é o mundo" passando pelo domínio de "o que sabemos sobre ele". Segundo essa perspectiva, o RC distingue duas dimensões do conhecimento: uma intransitiva e outra transitiva. A primeira dimensão refere-se à realidade independente do ser ou dos objetos do mundo (dimensão ontológica). A segunda refere-se a nosso conhecimento sobre a realidade ou sobre os objetos (dimensão epistemológica). Assim, quando reduzimos a realidade (dimensão intransitiva e ontológica) a nosso conhecimento sobre a realidade (dimensão transitiva e epistemológica), incorremos num erro epistêmico. Essa postura distancia o RC do realismo empírico, que identifica o real com o empírico, "como se o mundo correspondesse ao espectro de nossos sentidos, sendo idêntico àquilo que experimentamos" (Sayer, 2000: 09).

Para o RC, como já foi comentado na seção 1.2, pesquisas sociais não podem ser feitas pela investigação de eventos que se sucedem com regularida- 
des empiricamente observáveis, uma vez que eventos sociais, por não serem pré-determinados e dependerem de condições contingentes, podem ocorrer de muitas maneiras diferentes (Sayer, 2000: 14-15). A constituição do mundo social, como um sistema aberto em que um mesmo poder causal pode produzir inúmeros resultados diferentes, pressupõe um movimento transformacional entre a ação humana e a estrutura social.

\subsection{Concepção transformacional de constituição da sociedade}

O RC trabalha com um modelo transformacional de constituição da sociedade (Transformational Model of the Society/Person Connection), que difere dos modelos do "voluntarismo", de "reificação", e até mesmo do "dialético". Segundo Bhaskar (1989: 32-37)", no modelo do voluntarismo, objetos sociais são resultado do comportamento intencional de indivíduos. No modelo de reificação, objetos sociais são externos e exercem coerção sobre indivíduos. No modelo dialético, por sua vez, "sociedades" e "indivíduos" são dois momentos de um mesmo processo: as sociedades criam indivíduos, e indivíduos afetam as sociedades. A sociedade é criação dos seres humanos, mas não recurso para suas atividades. Nos termos de Bhaskar, "no primeiro modelo, há ações, mas não condições. No segundo modelo, há condições, mas não ações. No terceiro modelo, por sua vez, não há distinção entre ações e condições”.

Curry (2000: 102) observa grande afinidade entre o modelo transformacional e o dialético, mas pontua que o dialético difere do transformacional no "aspecto crucial da irredutibilidade das estruturas aos agentes que as transformam". Isso significa que, no modelo transformacional, a sociedade não é criação dos seres humanos, mas pré-existe a eles. A sociedade existe em virtude da agência humana, mas não é redutível a ela, e vice-versa. Como Sayer (2000: 19) exemplifica, ações sempre pressupõem recursos pré-existentes e meios: "falar pressupõe uma língua; uma língua, uma comunidade e recursos materiais, como cordas vocais ou outros meios de se efetuar sons inteligíveis (...)".

Na concepção transformacional, "sociedades" e "indivíduos", ou "estruturas" ("conjuntos de regras e recursos implicados, de modo recursivo, na reprodução social") e "agência humana" ("capacidade das pessoas para realizar

${ }^{6}$ Citado em Collier (1994: 144-145). 
as coisas") (Giddens, 2003: xxxv -10$)^{7}$, não são redutíveis a um, mas, sim, causalmente interdependentes. A propriedade da estrutura social de ser tanto meio para a agência humana quanto resultado da ação que ela recursivamente organiza é designada por Giddens (2003: 25-39) como "dualidade da estrutura". Essa dualidade, e não dualismo, implica considerar estruturas como "conjuntos de regras e recursos implicados, de modo recursivo, na reprodução social". Regras, que correspondem a "técnicas ou procedimentos generalizáveis aplicados no desempenho/reprodução de práticas sociais", a exemplo de normas lingüísticas, e recursos, que se referem à capacidade de gerar controle sobre objetos, bens, pessoas são propriedades estruturadoras e resultantes da ação humana. Sociedade é, nos termos de Bhaskar (1989: 34-35),

tanto a condição sempre presente (causa material) e o resultado continuamente reproduzido da agência humana. E práxis é tanto produção consciente, e reprodução (normalmente inconsciente) das condições de produção, que é a sociedade. O primeiro refere-se à dualidade da estrutura, e o último à dualidade da práxis.

No modelo transformacional, a relação entre estrutura e agência tem caráter dual: estrutura é condição, causa material, mas também é resultado da atividade humana, a qual, por sua vez, produz e reproduz essa causa material. A concepção de que seres humanos não criam estruturas sociais, mas as (re)produzem à medida que as utilizam como condições para suas atividades é representada no seguinte modelo transformacional de constituição da sociedade:

Figura 1 - Modelo transformacional de constituição da sociedade ${ }^{8}$

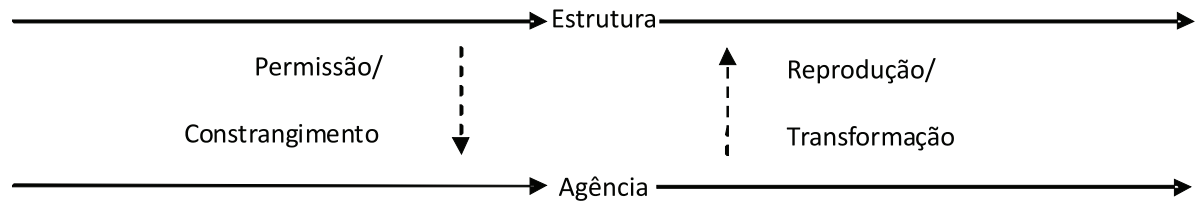

${ }^{7}$ Diversos autores têm apontado relações de parentesco entre o naturalismo crítico de Bhaskar e a teoria da estruturação de Giddens, a exemplo de Chouliaraki \& Fairclough (1999), Danermark, et al, (2002), Curry (2000) e Tozzi (2000).

${ }^{8}$ Com base em Bhaskar (1993: 155), recuperado em Danermark, et al. (2002: 179). 
O modelo sugere que a estrutura social existe somente como traços de memória e como exemplificada na ação, e não pode ser equiparada a restrição, a coerção, porque é sempre, simultaneamente, restritiva e facilitadora (Giddens, 2003). Por um lado, segundo o movimento descendente da seta, a ação humana depende de regras e recursos (incluindo mecanismos e seus poderes causais) disponíveis na estrutura social, mas ao mesmo tempo em que essa estrutura, na qualidade de meio, é facilitadora, por permitir a ação, ela também é constrangedora, pois, de certa forma, "regula" condutas. Por outro lado, segundo o movimento ascendente da seta, o uso de regras e recursos de estruturas sociais por atores sociais pode resultar em reprodução ou transformação de tal estrutura, como resultado. Assim, ação e estrutura constituem-se transformacional e reciprocamente, de maneira que uma não pode ser separada da outra nem reduzida a ela. Atores sociais, à medida que agem, fazem uso da estrutura social, (re)articulando mecanismos e poderes causais, e a (re)produzem, gerando no mundo diversos efeitos imprevisíveis.

A concepção transformacional implica a existência de uma entidade intermediária muito cara para a ADC: as práticas sociais. Por esse motivo, reservo a discussão sobre elas para a seção 2.3, específica para o assunto.

Considerando esses princípios epistemológicos e ontológicos, o RC propõe uma abordagem crítico-explanatória para estudos sociais, que procura contemplar a natureza estratificada da realidade, incluindo as entidades, estruturas e mecanismos (visíveis ou invisíveis) que existem e operam no mundo (Bhaskar, 1989: 12).

\subsection{Abordagem teórico-metodológica do Realismo Crítico}

Embora, como Sayer (2000: 20) observa, "o realismo critico endosse uma gama relativamente ampla de métodos de pesquisa”, investigações orientadas pela proposta teórico-metodológica do RC baseiam-se em análises de mecanismos causais e de seus efeitos potenciais em determinados contextos. Nos termos de Danermark et al. (2002: 20), baseiam-se na "investigação e identificação de relações e não-relações entre o que nós experienciamos, o que acontece no nível dos eventos, o que acontece no nível real e os mecanismos subjacentes que produzem efeitos mundo". 
A tarefa da pesquisa social orientada pelo RC é, a partir dos domínios actual e empírico, investigar mecanismos causais que operam em nível real, gerando efeitos particulares em sociedades, com atenção voltada, sobretudo, para causas e efeitos envolvidos em relações de poder. Para tanto, o RC dispõe de um "modelo básico, composto por seis passos, por meio do qual pesquisadores podem investigar estruturas e mecanismos, com objetivos emancipatórios" (Danermark et al., 2002: 193):

Quadro 2 - Modelo básico do Realismo Crítico para pesquisas

\begin{tabular}{|l|}
\hline Descrição do evento que é objeto de investigação \\
\hline Divisão analítica do evento em seus componentes \\
\hline Re-descrição desses componentes segundo teorias de estruturas e relações \\
\hline Busca de mecanismos que subjazem ao evento \\
\hline Avaliação do poder explanatório desses mecanismos \\
\hline Verificação das maneiras como os mecanismos envolvidos produzem o evento \\
\hline
\end{tabular}

A pesquisa social, segundo tal modelo, parte da abstração de eventos concretos da vida social, com o objetivo de compreender a natureza pré-estruturada da vida social, e retorna à análise de eventos, de ações e processos à luz desse conhecimento. Como se assume que o mundo tem profundidade ontológica, ou seja, que "eventos derivam da operação de mecanismos, os quais, por sua vez, derivam das estruturas dos objetos, e estes se localizam em contextos geo-históricos", a ausência de regularidades observáveis é esperada (Sayer, 2000: 15). Portanto, não se buscam regularidades neste tipo de pesquisa, e, sim, conexões causais entre fenômenos.

A busca por tais conexões não pode ser feita, segundo o RC, por meio da investigação de freqüências de eventos, mas, sim, pela "identificação de mecanismos causais, de como eles operam, e da descoberta de se eles foram ativados e sob quais condições" (Sayer, 2000: 13). Como Venkatraman (2000: 120) descreve, "deve-se mover do nível dos eventos (...) em direção a um nível 'mais profundo', de forma a se explicar os eventos observados e identificar os mecanismos causais que dão origem a fenômenos observados". A esse objetivo de explicar eventos e identificar mecanismos causais que originam fenômenos, subjaz a intenção emancipatória desse tipo de pesquisa. Sayer (2000: 20) 
ilustra que práticas sociais são informadas por idéias que podem ou não ser verdadeiras, e isso pode ter algum efeito naquilo que acontece. Relações de gênero social baseadas na crença de que gênero é algo natural e não produto de socialização, por exemplo, têm implicações na reprodução da desigualdade social entre homens e mulheres. A tarefa emancipatória do RC seria identificar compreensões sociais falsas e, conseqüentemente, ações falsamente embasadas, e mostrar que estas compreensões e ações devem ser mudadas.

Como a proposta deste trabalho é levantar pontos de diálogo entre a ADC e o RC, passo a confrontar aspectos teórico-metodológicos das duas propostas para estudos críticos da sociedade.

\section{Análise de Discurso Crítica e Realismo Crítico}

ADC é, em linhas gerais, uma abordagem científica transdisciplinar para estudos que se ocupam de alguma forma com a linguagem/semiose como prática social, que não só é constituída socialmente, como também é constitutiva de "identidades, relações sociais e sistemas de conhecimento e crença" (Fairclough, 1995: 131). A ADC parte da percepção de semiose como um estrato da realidade, o estrato semiótico, e como um momento de práticas sociais, que constitui outros momentos não-semióticos, assim como é constituído por eles. Por isso, considera que "questões sociais são, em parte, questões sobre discurso" (Chouliaraki \& Fairclough, 1999: vii). Tanto o ponto de partida em "práticas sociais", em vez de "estruturas sociais" ou "sujeitos" isolados, quanto a visão de semiose como um momento irredutível da vida social, que tem efeitos em sociedades e vice-versa, assim como sua proposta de abordagem teórico-metodológica, por exemplo, encontram inspiração no RC.

Pode-se dizer, sucintamente, que a principal tarefa da ADC, como ciência social crítica, é mapear conexões entre semiose e (aspectos não-semióticos da) sociedade, com o objetivo de, primeiro, localizar mecanismos semióticos, e suas causas e efeitos de sentido potencialmente ideológicos, para, em seguida, suscitar possíveis maneiras de superar relações assimétricas de poder parcialmente sustentadas pela linguagem. Essa tarefa encontra subsídios na operacionalização do RC, o que implica superar fronteiras entre disciplinas e transformá-las, ao contrário de, simplesmente, aplicá-las (Fairclough, 2003). 


\subsection{Diálogos transdisciplinares}

Embora o diálogo com o RC já estivesse presente em outros trabalhos de Fairclough, a exemplo de Discourse and social change (1992, tradução brasileira de 2001), tal influência torna-se mais explícita em trabalhos recentes, como Discourse in late modernity (Chouliaraki \& Fairclough, 1999), Critical Realism and semiosis (Fairclough, et. al. 2002), Analysing discourse (Fairclough, 2003), em que se encontra o arcabouço teórico-metodológico baseado no modelo do RC. Em Fairclough (2001: 108), lê-se:

textos apresentam resultados variáveis de natureza extradiscursiva, como também discursiva. Alguns textos conduzem a guerras ou à destruição de armas nucleares; outros levam as pessoas a perder o emprego ou a obtê-lo; outros ainda modificam as atitudes, as crenças ou as práticas das pessoas.

A passagem ilustra a preocupação da $\mathrm{ADC}$ de abordar a linguagem em termos crítico-realistas de causa e efeito no mundo, segundo a lógica relacional/ dialética da análise crítica, "orientada para mostrar como o momento discursivo trabalha na prática social, do ponto de vista de seus efeitos em lutas hegemônicas e relações de dominação" (Chouliaraki \& Fairclough, 1999: 67). Essa abordagem era feita, explicitamente, sobretudo com base em Gramsci $(1988: 423)^{9}$, que define hegemonia como "um contínuo processo de formação e suplantação de um equilíbrio instável". Como se observa, a visão gramsciana de sociedade também é a de um sistema aberto. Ativações de poderes causais por atores sociais, em situações e contextos particulares (agência humana) podem reestruturar, transformar ou destituir o poder hegemônico vigente (na estrutura).

Mais recentemente, a partir do trabalho de Chouliaraki \& Fairclough (1999), nota-se na ADC uma aproximação mais explícita de teóricos sociais contemporâneos, a exemplo de Bhaskar. Nas passagens seguintes, Fairclough (2003: 14) define claramente sua postura realista:

\footnotetext{
${ }^{9}$ Muito embora Chouliaraki \& Fairclough (1999: 35) observem que Gramsci (1988), assim como Giddens (2003) e Bhaskar (1989), dentre outros, inspiram-se na mesma 'filosofia da práxis', de Marx.
} 
A posição que adoto é realista, baseada em uma ontologia realista: tanto eventos sociais concretos quanto estruturas sociais abstratas, assim como as menos abstratas "práticas sociais" [...], são parte da realidade.

Minha motivação em levantar essas questões é a crença de que textos têm conseqüências e efeitos sociais, políticos, cognitivos, morais e materiais, e de que é vital compreender esses efeitos se pretendemos levantar questões políticas e morais a respeito das sociedades contemporâneas [...].

Minha abordagem insere-se amplamente na tradição da 'ciência social crítica' - ciência social motivada pelo objetivo de prover base cientifica para um questionamento crítico da vida social em termos políticos e morais, ou seja, em termos de justiça social e poder.

Operacionalizando, portanto, a noção de poder hegemônico de Gramsci, mas também, dentre outras, de vida social como um sistema aberto, de Bhaskar, e de prática social de Harvey (1996), conforme apontam Resende \& Ramalho (2006), a ADC concebe a linguagem como um momento irredutível de práticas sociais, que tem conseqüências e efeitos em sociedades, incluindo lutas hegemônicas e relações de dominação.

Na seção 1.4, em que discuti a concepção transformacional de constituição da sociedade, propositalmente não foi desenvolvida uma discussão mais detida sobre a entidade social intermediária à estrutura e à agência, qual seja, a prática social. Uma vez que a noção dessa entidade é essencial para a concepção de linguagem adotada pela ADC, reservei a discussão para as seções seguintes.

\subsection{Ontologia estratificada e níveis da composição social}

Como se discutiu, para o modelo transformacional, ação e estrutura constituem-se reciprocamente, de maneira que uma não pode ser separada da outra, nem reduzida a outra. À medida que agem no mundo, indivíduos fazem uso da estrutura social e ao mesmo tempo a (re)produzem. Maneiras recorrentes, situadas temporal e espacialmente, pelas quais indivíduos aplicam recursos da 
estrutura para interagirem no mundo pressupõem a existência de (redes de) práticas sociais - uma entidade que, em virtude de sua posição, incorpora aspectos tanto de estruturas mais abstratas quanto de eventos concretos. Práticas sociais representam, portanto, uma entidade social intermediária, situada entre estruturas (mais abstratas, e estáveis, em termos de relativa permanência) e eventos concretos, ou experienciados por atores (mais concretos e flexíveis).

Com base na estratificação ontológica proposta pelo RC, é possível sugerir uma aproximação moderada entre os domínios real, actual, empírico e os três níveis do social, conforme ilustra o Quadro 3:

Quadro 3 - Níveis do social, segundo a ontologia estratificada

Estrutura Práticas sociais Eventos concretos

\section{Mecanismos}

Eventos

Experiências

Partindo do nível mais abstrato para o mais concreto, temos o nível da estrutura, relacionado ao domínio do real (cf. Quadro1), em que estão os objetos de diversos estratos, suas estruturas, mecanismos e poderes causais. A ativação desses poderes gera diferentes efeitos causais em eventos, experienciados ou não, por isso a presença de estruturas, com seus poderes e efeitos, estende-se a eventos e experiências.

No nível das (redes de) práticas sociais - e não de uma prática social particular, uma vez que várias práticas, de diversos campos sociais, articulam-se simultaneamente -, relacionado ao domínio do actual, estão os eventos, que acontecem independente de nossas experiências, quando poderes causais são ativados. Neste nível, que se localiza entre o mais abstrato (estrutura) e o mais concreto (eventos), estão as "maneiras habituais, em tempos e espaços particulares, pelas quais pessoas aplicam recursos para interagirem no mundo" (Chouliaraki \& Fairclough, 1999: 21), que Giddens (2003) reconhece como o domínio básico de estudo das ciências sociais.

No nível dos eventos concretos, relacionado ao domínio do empírico, estão as experiências efetivas, a parte do real e do actual que é experienciada por atores sociais particulares, a exemplo de cientistas que trabalham com material 
empírico. O termo "concretos" aqui é muito importante não só para elucidar a existência de eventos não experienciados por atores particulares no domínio do actual, mas também para destacar que aquilo que se experiencia não esgota a possibilidade do que aconteceu ou poderia ter acontecido.

Para a ADC, a linguagem manifesta-se nesses três níveis do social, relacionados com os três domínios ontológicos.

\subsection{Linguagem como prática social}

Para analistas críticos de discurso, o mais importante não é a linguagem nem como estrutura nem como ação individual, mas, antes, como prática social. A importância desta entidade social intermediária para a ADC, assim como para a ciência social crítica, decorre de sua qualidade de "ponto de conexão entre estruturas abstratas e seus mecanismos, e eventos concretos - entre 'sociedade' e pessoas vivendo suas vidas" (Chouliaraki \& Fairclough, 1999: 21). A percepção de vida social organizada em torno de práticas sociais ajuda a evitar o foco estrito na agência humana ou em textos, por um lado, e na estrutura ou no sistema lingüístico, por outro. Conforme já foi comentado, o conceito de práticas sociais, operacionalizado em ADC, encontra inspiração não só em Bhaskar, mas também em Harvey (1996).

Como maneiras recorrentes, situadas temporal e espacialmente, pelas quais pessoas interagem no mundo, acionando estruturas e seus mecanismos gerativos, práticas sociais são "articulações de diferentes tipos de elementos sociais que são associados a áreas particulares da vida social" (Fairclough, 2003: 25). Qualquer prática, segundo Fairclough (2003), com base em Harvey (1996), envolve ação e interação; relações sociais; pessoas (com crenças, valores, atitudes, histórias etc.); mundo material e discurso. Em práticas particulares, esses cinco elementos mantêm entre si constantes relações dialéticas de articulação e internalização, sem se reduzirem a um, tornando-se "momentos" da prática. Resende \& Ramalho (2004, 2006) explicam que essas relações dialéticas de articulação e internalização entre os cinco momentos de práticas sociais particulares podem ser tanto minimizadas para se aplicar à articulação interna de cada momento de uma prática, quanto ampliadas para se aplicar à articulação externa entre práticas organizadas em redes. No primeiro caso, tomando como 
exemplo o momento discursivo de práticas, há relações dialéticas entre seus três momentos internos: gêneros, discursos, estilos. No segundo caso, relações dialéticas entre diferentes práticas, associadas a diferentes campos sociais, formam redes das quais as próprias práticas passam a constituir momentos.

O conceito de articulação, de Laclau \& Mouffe (2004: 142-3), que se refere a "toda prática que estabelece uma relação tal entre elementos que resulta na modificação da identidade desses elementos", ajuda a entender, por exemplo, como traços tanto de momentos de amplas redes de práticas sociais, quanto de momentos de práticas particulares podem ser articulados com momentos internos (gêneros, discursos e estilos) do momento discursivo, internalizando traços um do outro, sem se reduzirem a um, e vice-versa. Em outros termos, ajuda a explicar a conexão, em termos de causa e efeito, entre elementos discursivos e não-discursivos de práticas sociais. A linguagem, segundo tal concepção, é um momento de (redes de) práticas sociais, que mantém relações de articulação e internalização simultâneas com outros momentos não-semióticos. Nessas relações, incorpora traços do social, assim como gera efeitos no mundo.

Embora o foco da ADC seja em práticas sociais, isso não significa que a linguagem esteja presente apenas neste nível. Como Fairclough (2003: 24) sustenta, a linguagem é um elemento do social em todos os níveis: da estrutura social, das práticas sociais e dos eventos sociais, como o Quadro 4, a seguir, representa:

Quadro 4 - Linguagem como um elemento do social em todos os níveis

\section{Sistema Ordens de discurso Textos}

\section{Mecanismos}

Eventos

Experiências

O Quadro 4, inspirado na estratificação ontológica proposta pelo RC, assim como o Quadro 3, aproxima os domínios real, actual, empírico aos três níveis do social, e apresenta a linguagem como um elemento constituinte de todos eles.

Primeiro, no nível da estrutura, a linguagem manifesta-se como estrato semiótico, ou sistema - uma rede de opções que constituem recursos aos quais 
o falante recorre para construir significados em suas interações diárias, com seus mecanismos e poderes, que geram efeitos em estratos não-semióticos, assim como é afetado por eles. Esse sistema, segundo a Lingüística SistêmicoFuncional (LSF), é aberto e composto por diferentes estratos: fonético, fonológico, lexicogramatical e semântico (Halliday \& Mattiessen, 2004: 25). A LSF concebe a linguagem como um sistema semiótico complexo, aberto - na medida em que a rede de opções, em interface com o contexto, garante a capacidade ilimitada da linguagem para a construção de significados -, e estruturado em estratos internos (fonético, fonológico, lexicogramatical e semântico), em interface com o externo (contexto). Em Halliday \& Matthiessen (2004: 25), encontramos uma representação desses estratos, adaptada aqui:

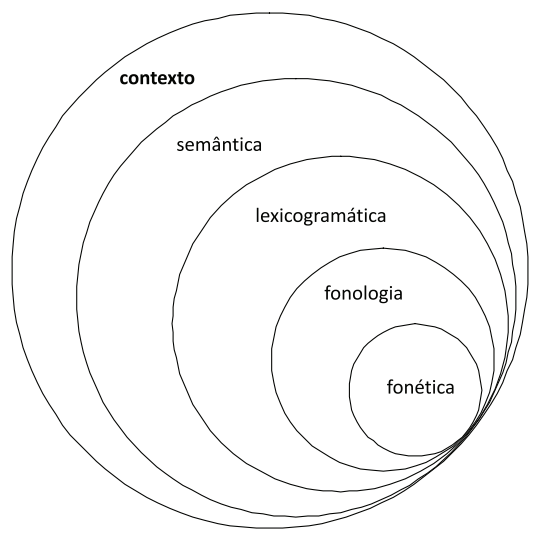

Figura 2 - Estratificação da linguagem

Nas atividades humanas que envolvem linguagem, acionamos todos esses estratos simultaneamente. De maneira simplificada, segundo a LSF, os significados (estrato semântico) são realizados por palavras, orações (estrato lexicogramatical), cuja expressão se dá via fala ou escrita (estratos fonético, fonológico ou grafológico). Significados e expressões articulam-se com o estrato extralingüístico, uma vez que escolhas de recursos, disponíveis na rede de opções, são permitidos e constrangidos pelo contexto (de situação), que compreende três variáveis, importantes para a interação humana pela linguagem: a natureza da prática social (campo), a natureza da conexão entre os participantes da situação (relação) e a natureza da transmissão da mensagem (modo). 
A LSF considera que um desses estratos - o lexicogramatical -, embora não se relacione diretamente com o extralingüístico, é formado historicamente por processos de "semogênese" - a produção histórica e a mudança do semiótico -, que tornam o sistema lingüístico aberto à adaptação social (Hasan, no prelo b $)^{10}$. A semogênese - formada pela lógica, ou "poder gerativo", nos termos do RC, do social ("sociológica") e pela lógica, ou poder gerativo, do semiótico ("semológica") - permite que o potencial de significado de uma língua estenda-se, mais ou menos indefinidamente. Esse potencial relaciona-se com as três variáveis do contexto de situação (campo, relação e modo), que, por sua vez, realizam-se por meio das (macro)funções que a linguagem desempenha, simultaneamente, na vida humana: a função ideacional, pela qual construímos e representamos a experiência de mundo interior e exterior, a função interpessoal, pela qual estabelecemos relações sociais, e, por fim, a função textual, pela qual estruturamos significados em textos.

Segundo, no nível das práticas sociais, a linguagem manifesta-se como ordem de discurso - "uma combinação particular ou configuração de gêneros, discursos e estilos, que constitui o aspecto discursivo de redes de práticas sociais (Fairclough, 2003: 220). Note que nesse domínio a linguagem assume a forma de "discurso", o momento semiótico de práticas sociais. A ADC advoga que ordens de discurso, assim como o sistema semiótico, também constituem redes potenciais de opções, e, portanto, de significados. A linguagem, como explicam Chouliaraki \& Fairclough (1999: 151-2),

como um sistema aberto, tem capacidade ilimitada para a construção de significado através de conexões gerativas sintagmáticas e paradigmáticas, mas é o dinamismo da ordem do discurso, capaz de gerar novas articulações de discursos e gêneros, que mantém a linguagem como um sistema aberto (...) Por outro lado, é a fixidez da ordem do discurso que limita o poder gerativo da linguagem, impedindo certas conexões.

A rede de opções de ordens de discurso não é formada por orações, palavras (ainda que a origem dessa segunda rede seja possibilitada pela primeira), mas, sim, por gêneros, "tipos de linguagem ligados a uma atividade social

\footnotetext{
${ }^{10}$ Citado em Fairclough (2003: 139).
} 
particular", discursos, "tipo de linguagem usado para construir algum aspecto da realidade de uma perspectiva particular", e estilos, "tipo de linguagem usado por uma categoria particular de pessoas e relacionado com sua identidade" (Chouliaraki \& Fairclough, 1999: 63). Assim como a rede de opções de recursos fonéticos, fonológicos, lexicogramaticais e semânticos, esses três elementos também figuram em práticas como recursos para a ação humana, e como resultado dela. Sendo assim, o sistema aberto da linguagem é mantido não só pelos recursos disponíveis "dentro" do sistema, mas também pelo dinamismo das ordens de discurso. Novas articulações de discursos, gêneros e estilos de diferentes ordens de discurso também contribuem para a construção de significados. Isso significa, primeiro, que o poder gerativo do semiótico é mediado pelo poder gerativo de outros momentos do social e, segundo, que a semiose tem estrutura dupla, formada pela rede de opções do sistema lingüístico e das ordens de discurso.

Por fim, no nível dos eventos concretos, a linguagem manifesta-se como texto, o material empírico de eventos que ocorrem em (redes de) práticas sociais mais amplas. Traços de movimentos articulatórios entre mecanismos sociais semióticos e não-semióticos, incluindo mecanismos de ordens de discurso, são materializados em textos, cujos sentidos potenciais, por sua vez, geram efeitos em sociedades. A semiose, como destaca Fairclough et. al (2002: 09), tem

seus próprios elementos distintivos, propriedades e efeitos emergentes e mesmo que (e precisamente por isso) esses elementos e seus poderes causais interpenetrem, interfiram e sobredeterminem outros tipos de relações sociais e de ordens institucionais, eles devem ser integrados em análises crítico-realistas mais detalhadas do mundo social.

Uma vez que a linguagem é vista como um elemento constituinte do social e constituído por ele, a ADC preocupa-se em mapear conexões entre aspectos sociais semióticos e não-semióticos. A tarefa do(a) analista de discurso não se limita à investigação de causas e efeitos do social na linguagem, a exemplo de mudanças em gêneros discursivos, de criação de tecnologias discursivas, mas também inclui investigações sobre causas e efeitos da semiose no social, a exemplo de desigualdade social, guerras, desemprego. Isso significa que, 
embora textos representem o principal material empírico com que o(a) analista de discurso trabalha, análises textuais não são suficientes para captar conexões entre linguagem e (aspectos não-semióticos da) sociedade.

Para tanto, a ADC recorre ao tipo de abordagem teórico-metodológica “crítica explanatória”, que considera vários níveis da realidade, com seus mecanismos gerativos, que produzem efeitos no mundo.

\subsection{Proposta teórico-metodológica da Análise de Discurso Crítica}

Por reconhecer que o social é um sistema aberto e estratificado e que, portanto, "a atividade científica deve estar comprometida com níveis mais profundos, suas entidades, estruturas e mecanismos (visíveis e invisíveis) que existem e operam no mundo" (Bhaskar, 1989: 12), a ADC propõe uma abordagem teórico-metodológica potencialmente capaz de alcançar esses níveis. Com base no RC, Fairclough (2003: 14) distingue

o 'real' ${ }^{11}$ e o 'actual' - o que é possível dada a natureza (constrangimento e permissão) de estruturas e práticas sociais, em oposição ao que de fato acontece. Ambos - potencial e real - devem ser distinguidos do 'empírico', o que sabemos sobre a realidade. [...] A realidade [...] não pode ser reduzida ao nosso conhecimento sobre ela, que é contingente, mutável e parcial. Isso também se aplica a textos: não devemos presumir que a realidade de textos seja exaurida por nosso conhecimento sobre eles. Uma conseqüência disso é que devemos assumir que nenhuma análise de um tex to pode dizer tudo o que há para ser dito sobre ele - não existe análise completa e definitiva de um texto. O conhecimento social científico de textos é possível, mas inevitavelmente parcial.[...]

E, por meio dessa distinção, o autor observa que a análise textual é

inevitavelmente seletiva: em toda análise, escolhemos responder a determinadas questões sobre eventos sociais e textos, e não a outras

\footnotetext{
${ }^{11} \mathrm{O}$ autor usa o termo potential para se referir ao real, utilizado por Bhaskar (1989) e mantido neste trabalho.
} 
questões possíveis. Há sempre motivações particulares na escolha de certas questões sobre textos e não outras. [...] Não existe análise 'objetiva' de um texto, pois não é possível descrever simplesmente 'o que está lá' sem a participação "tendenciosa" da "subjetividade" do analista. [...] nossa capacidade de saber 'o que está lá' é inevitavelmente limitada e parcial, e a questão que procuramos responder deriva necessariamente de motivações particulares.

Os comentários destacam as limitações do trabalho, isolado, de análise textual. Assim como não é possível reduzir a realidade a o que sabemos sobre ela, também não é possível fazer análises completas, definitivas e "objetivas" de textos, uma vez que elas são sempre parciais, seletivas, motivadas por interesses do(a) pesquisador(a). Além disso, análises de textos são insuficientes para alcançar níveis mais profundos da realidade, envolvidos na produção desse material empírico.

Chouliaraki e Fairclough (1999: 67-68) observam que a interpretação de textos é um processo complexo que engloba duas partes: a compreensão e a explanação. Um texto pode ser compreendido de diferentes maneiras, uma vez que diferentes combinações das propriedades do texto e do posicionamento social, conhecimentos, experiências e crenças do leitor resultam em diferentes compreensões. Parte desse trabalho, portanto, é análise de compreensões, o que envolve descrições e interpretações. Entretanto, a ADC, como esclarecem os autores,

não advoga uma compreensão particular do texto, mas uma explanação particular. Uma explanação re-descreve propriedades de um texto (incluindo o conjunto de compreensões), usando um arcabouço teórico particular para localizar o texto na prática social. [...] os conceitos do arcabouço são relacionados a material empírico, construindo o objeto de pesquisa (as relações relevantes para a análise), seu funcionamento (como essas relações são articuladas), bem como suas potencialidades (não apenas seus efeitos reais, mas também sua função potencial). 
À compreensão, soma-se a explanação, que reside na interface entre conceitos e material empírico, por meio da qual conceitos são usados para re-descrever propriedades de textos, localizando-os na prática social. A Quadro 5 apresenta o arcabouço teórico-metodológico da ADC, que procura contemplar análises textual e socialmente orientadas:

Quadro 5 - Arcabouço teórico-metodológico da Análise de Discurso Crítica

\begin{tabular}{|l|}
\hline Percepção de um problema social com aspectos semióticos \\
\hline $\begin{array}{r}\text { Identificação de obstáculos para que o problema seja superado } \\
\text { análise da conjuntura } \\
\text { análise da prática particular } \\
\text { análise do discurso }\end{array}$ \\
\hline Investigação da função do problema na prática \\
\hline Investigação de possíveis modos de ultrapassar os obstáculos \\
\hline Reflexão sobre a análise \\
\hline
\end{tabular}

Fonte: Chouliaraki \& Fairclough (1999: 60) e Fairclough (2003: 209-210).

Com base na "versão de 'crítica explanatória' desenvolvida por Bhaskar" (Fairclough, 2003: 209), cuja tarefa principal é a explanação de fenômenos sociais por meio da investigação de mecanismos causais que os produzem, esse arcabouço propõe que a análise de discurso parta da percepção de um problemasocial comaspectos semióticos. Emseguida, identificam-seobstáculos para que o problema seja superado, isto é, características relativamente permanentes nas redes de práticas que sustentam o problema observado, através de três focos de análise: análise da conjuntura, análise da prática particulare análise do discurso. Nesta etapa, investigam-se mais detalhadamente relações de causa e efeito entre redes mais amplas de práticas (conjunturas), passando por práticas particulares, até chegar ao discurso. Essas duas etapas aproximam-se dos passos da "descrição do evento que é objeto de investigação", "da divisão analítica do evento em seus componentes", da "re-descrição dos componentes segundo teorias de estruturas e relações", e da "busca de mecanismos que subjazem ao evento", do RC (cf. Quadro 2). 
As etapas seguintes do arcabouço da ADC relacionam-se à investigação das funções do problema na prática e das possíveis maneiras de superaros obstáculos que sustentam o problema social de cunho semiótico. Essas duas etapas aproximam-se dos passos da "avaliação do poder explanatório dos mecanismos que subjazem ao evento" e da "verificação das maneiras como os mecanismos envolvidos produzem o evento em questão", do RC, uma vez que a intenção aqui é investigar causas e efeitos desse problema na prática social e identificar mecanismos que o sustentam, a fim de desestabilizá-los. Por fim, o arcabouço propõe a reflexão sobre a análise, etapa que deve compor toda pesquisa crítica, a fim de questionar a si mesma a respeito de sua eficácia e contribuição para questões de emancipação social.

Assim, com base na versão de crítica explanatória do RC, pesquisas em ADC objetivam investigar relações dialéticas entre semiose e outros momentos que compõem (redes de) práticas sociais, a fim de identificar mecanismos semióticos e efeitos de sentido que possam contribuir para instauração ou sustentação de relações assimétricas de poder. E, por meio dessa identificação de causas e efeitos de sentidos de textos, "levantar questões políticas e morais a respeito das sociedades contemporâneas" (Fairclough, 2003: 14).

\section{CONSIDERAÇÕES FINAIS}

Neste trabalho procurei discutir aspectos do diálogo teórico-metodológico que ADC mantém com o RC. Observa-se que o RC traz contribuições significativas para a concretização da proposta da ADC de mapear mecanismos discursivos e suas causas e efeitos de sentido potencialmente ideológicos, a fim de suscitar possíveis maneiras de superar relações assimétricas de poder parcialmente sustentadas pela linguagem. O RC contribui, direta ou indiretamente, para explicar alguns pontos centrais para a ADC: primeiro, por que a linguagem internaliza traços de outros momentos de práticas sociais e vice-versa. Segundo, por que a abordagem da língua como sistema não é suficiente para este tipo de pesquisa. Terceiro, por que sociedades devem ser vistas como sistemas abertos e não como produtos acabados. Quarto, por que a suposta "objetividade" em pesquisas sociais é um tema a ser superado, sob pena de se incorrer numa "falácia epistêmica", dentre outros. Entretanto, como observa Fairclough (2002: 09), a ADC também pode contribuir 
significativamente para investigações crítico-realistas mais detalhadas do mundo social, que contemplem discussões sobre linguagem.

\section{REFERÊNCIAS BIBLIOGRÁFICAS}

BHASKAR, R. A realist theory of science. Brighton: Harvester: 1978.

BHASKAR, R. The possibility of naturalism. Hemel Hempstead: Harvester Wheatsheaf, 1989.

BHASKAR, R. Dialectic: the pulse of freedom, London: Verso, 1993.

BHASKAR, R. \& A. CALLINICOS. Marxism and Critical Realism: a debate. Journal of Critical Realism, 1(2): 89-114, 2003.

CHOULIARAKI, L. \& N. FAIRCLOUGH. Discourse in late modernity: rethinking Critical Discourse Analysis. Edinburgh: Edinburgh University Press, 1999.

COLLIER, A. Critical Realism: an introduction to Roy Bhaskar's philosophy. London: Verso, 1994.

CURRY, N. Marxismo, Pós-marxismo e Realismo Crítico: reflexões acerca do debate Bhaskar/Laclau. Estudos de Sociologia. Revista do Programa de PósGraduação em Sociologia da UFPE, 6(2): 97-115, 2000.

DANERMARK, B. et al. Explaining society: Critical Realism in the social sciences. London; New York: Routledge, 2002.

FAIRCLOUGH, N. Language and power. London: Longman, 1989.

FAIRCLOUGH, N. Critical discourse analysis: papers in the critical study of language. New York: Longman, 1995.

FAIRCLOUGH, N. Discurso e mudança social. Brasília: Universidade de Brasília, 2001.

FAIRCLOUGH, N. Analysing discourse: textual analysis for social research. London: Routledge, 2003.

FAIRCLOUGH, N. et al. Critical Realism and semiosis. Journal of Critical Realism, Alethia, 5(1): 2-10, 2002.

GIDDENS, A. A constituição da sociedade. São Paulo: Martins Fontes, 2003.

GRAMSCI, A. A Gramsci reader: selected writings 1916-1935. In: D. Forgacs. (org.) London: Lawrence and Wishart, 1988.

HALLIDAY, M. A. K. An introduction to Functional Grammar. 3 ed. revised by C. M. I. M. Matthiessen. London: Hodder Arnold, 2004. 
HARVEY, D. Justice, nature and the geography of a diference. London: Blackwell, 1996.

LACLAU, E. \& C. MOUFFE. Hegemonía y estrategia socialista: hacia una radicalización de la democracia. Buenos Aires: Fondo de Cultura Económica de Argentina, 2004.

RAMALHO, V. C. V. S. Constituição da Análise de Discurso Crítica: um percurso teórico-metodológico. Signótica, 17: 275-298, 2005.

RESENDE, V. M. \& V. C. V. S. RAMALHO. Análise de Discurso Crítica, do modelo tridimensional à articulação entre as práticas: implicações teóricometodológicas. Linguagem em (Dis)curso, 5: 185-207, 2004.

RESENDE, V. M. \& V. RAMALHO. Análise de Discurso Crítica. São Paulo: Contexto, 2006.

RIOS, J. A. Idealismo. In: Dicionário de Ciências Sociais. Rio de Janeiro: FVG, 1987, pp. 566-568.

SAYER, A. Características-chave do Realismo Crítico na prática: um breve resumo.EstudosdeSociologia.RevistadoProgramadePós-GraduaçãoemSociologia da UFPE, 6(2): 7-32, 2000.

TOZZI, V. Realismo Crítico e historiografia. Estudos de Sociologia. Revista do Programa de Pós-Graduação em Sociologia da UFPE, 6(2): 77-95, 2000.

VENKATRAMAN, S. Realismo Crítico e desenvolvimento rural no Sul da Índia.EstudosdeSociologia.RevistadoProgramadePós-GraduaçãoemSociologia da UFPE, 6(2): 117-135, 2000. 
RESENHAS 
